\title{
A New Learning Object Repository for Language Learning: Methods and Possible Outcomes
}

\author{
Catherine Caws \\ University of Victoria, \\ Victoria, BC, Canada \\ ccaws@uvic.ca
}

\author{
Norm Friesen \\ Simon Fraser University, \\ Burnaby, BC, Canada \\ norm friesen@sfu.ca
}

\author{
Martin Beaudoin \\ Faculté Saint-Jean, University of Alberta, \\ Edmonton, Alberta, Canada
}

martin.beaudoin@ualberta.ca

\begin{abstract}
Learning objects and repositories have been receiving more and more attention in the area of computer assisted language learning. The integration of learning object repositories into language programs presents both opportunities and challenges. This paper considers these as they arise specifically in conjunction with the development of an online collection of resources for teaching and learning French as a second language. This paper evaluates the specific characteristics of this new collection and focuses on the design and procedures used in the development of such a collection. The paper also outlines a program aimed at understanding the situated use of this collection of resources in French language learning contexts.
\end{abstract}

Keywords: learning objects, repositories, language learning, French, research design.

\section{Introduction}

Since the popular advent of the Internet some ten years ago, the use of online resources has become increasingly common in education --both in distance and classroom education and training settings. However, these technologies have typically been applied in ad hoc and divergent forms. Innumerable courses, course components and systems for managing and delivering course content have been developed independently of one another, often at great expense. The combination of reusable learning resources, systematic descriptions of their content and networked collections of these resources can together address these problems. This combination also has the potential to

Material published as part of this journal, either on-line or in print, is copyrighted by the publisher of the Interdisciplinary Journal of Knowledge and Learning Objects. Permission to make digital or paper copy of part or all of these works for personal or classroom use is granted without fee provided that the copies are not made or distributed for profit or commercial advantage AND that copies 1) bear this notice in full and 2) give the full citation on the first page. It is permissible to abstract these works so long as credit is given. To copy in all other cases or to republish or to post on a server or to redistribute to lists requires specific permission and payment of a fee. Contact Publisher@ijklo.org to request redistribution permission. lower course development and delivery costs while increasing quality, and ultimately to provide content and interaction directly suited to the needs and preferences of individual learners.

The term "learning object" (LO) has been widely used to designate individual instances of these resources. In computer science, "objects" are modular software components that can be used and combined for a variety of 
purposes. In education, learning objects are digital resources of any kind that can be similarly combined, shared and repurposed in different educational contexts (Harman \& Koohang, 2005). These resources are made accessible to teachers, students and other users through online portals, collections or "Learning Object Repositories (LORs)" which can be used either to store the objects themselves, or to store pointers or addresses for these resources (Namuth, Fritz, King, \& Boren, 2005). Repositories enable users to locate, evaluate and manage learning objects through the use of "metadata", namely descriptors or tags that systematically describe many aspects of a given learning object, from its technical to its pedagogical characteristics (McGreal \& Roberts, 2001; Richards, McGreal, Hatala \& Friesen, 2002).

Most of the research and writing on learning objects to date has been technical and promotional in emphasis (Friesen, 2004). It has focused on the development of infrastructures to support the organization and reuse of these resources between repositories. Although important, it has been noted that such work has neglected one key element in the "value proposition" presented by learning objects: learning (Rehak \& Mason, 2003).

This paper, together with the research project it outlines, intends to address this deficit. It describes the features of a learning object repository that is being developed specifically to support the teaching and learning of French as a second language. It also describes an associated program of research aimed at developing an understanding of how the advanced technologies of learning objects and repositories can be applied in everyday teaching and learning practices in this important subject area.

\section{LORs and their Challenges}

The learning object repository project described in this paper is named FLORE, short for "French Learning Object Repository for Education." A prototype of this collection can be accessed at http://flore.uvic.ca. One of the principal challenges that this project is trying to address has been identified in a number of recent publications discussing learning objects and pedagogy. This challenge can be identified as the issue of "pedagogical neutrality." Learning objects, and the technical systems that have been developed to support their use (e.g. repositories and related infrastructures), have been commonly described as being able to support any pedagogical approach, rather than being designed and tailored for particular educational methods and contexts. For example, Richards et al. (2002) explain that "although learning object repositories may provide a better means of discovering and distributing learning objects, repositories do not themselves address issues of pedagogy" (p.76). Software and conceptions of content that are intended to serve education and learning are commonly described as being themselves "instructionally" and "pedagogically neutral" or "agnostic" (Blandin, 2004; Wiley, 2005). Indeed, the smaller and more distinctly separate a learning object is from any one, particular educational context, the more it is seen as exemplifying the qualities of a reusable learning object. Mortimer (2002), for example, reflects on a vision of LOR that can handle context-free, interoperable chunks of information. As Wiley (2003) and Wiley, Recker and Gibbons (2000) point out, this leads to a paradoxical situation: On the one hand, resources for learning are decontextualized from learning as modular, selfcontained learning objects. But on the other hand, "context" itself is increasingly understood in psychological theory as the preeminent aspect of learning. While also reflecting on this paradoxical situation, Nash (2005) and others (e.g. de Salas \& Ellis, 2006) support the idea that the use of LORs in pedagogical settings must be reinforced by a clear and detailed learning design. These authors add that the learning theory adopted by course designers is at the very core of the application and organization of learning objects. Nash (2005), for example, rightly argues that, "without a solid connection with underlying learning theories, the use of learning objects quickly becomes a function of the technology rather than [of] the desired learning outcome" (p. 227). 
The question for designers and implementers of LORs then becomes: How can learning objects and repositories be conceptualized in a way that does not isolate or neutralize them in terms of their specific pedagogical contextualization and application?

\section{FLORE and its Metadata}

The FLORE repository attempts to address this issue. It is being developed as a collaborative project by researchers from the University of Victoria, Faculté Saint-Jean (University of Alberta) Simon Fraser University, and Athabasca University. FLORE provides organized access to nearly 900 resources relevant to teaching and learning French as a second language. This repository currently allows users to search these resources by title, description, URL, author, level of linguistic competence and keyword.

Despite offering these typical forms of access, FLORE differs from high profile repositories such as CAREO (www.careo.org), Wisc-online (http://www.wisc-online.com ) or MERLOT(www.merlot.org) in a number of ways:

a. It concentrates on one discipline only, French;

b. Correspondingly, the metadata it stores are tailored to the needs of those learning French as a second language (for instance, objects are described or categorized according to level of linguistic competency);

c. Emphasis is placed on the provision of access to specific or "granular" Web pages, or items embedded into Web pages, rather than to Web sites as a whole. A single Web site is often divided into multiple learning objects described individually in FLORE using separate metadata records to provide the most direct access to the user.

\section{Standards}

FLORE is explicitly standards-based. Its data storage and management components are being redesigned according to CanCore's recommendations on how to utilize the IEEE Learning Object Metadata Standard. This metadata standard, commonly known simply as the "LOM," (learning object meta-data), is now widely implemented and used for the systematic description of digital educational resources (Friesen, 2005). It is comprised of 76 data elements, including common cataloguing fields such as "title," "description," and "keywords," but also more obscure elements like "aggregation level" and "semantic density." CanCore (www.cancore.ca) provides an extensive set of guidelines for the implementation of these data elements --in both English and French. These CanCore guidelines have been utilized in FLORE. This was initially done through the development of a "crosswalk" showing the relationship between the data elements originally conceived for FLORE and their CanCore/LOM equivalents. This original crosswalk diagram is provided in Table 1.

Table 1: FLORE/ CANCORE LOM Equivalence

\begin{tabular}{|l|l|}
\hline FLORE ELEMENT & CanCore/LOM EQUIVALENT \\
\hline Titre & General. Title \\
\hline URL & Technical. Location \\
\hline Concepteurs & Life Cycle. Contribute. Entity \\
\hline Description & General. Description \\
\hline Domaines & General. Keyword \\
\hline $\begin{array}{l}\text { Niveau du public cible (Débutant, Inter- } \\
\text { médiaire, Avancé, Supérieur) }\end{array}$ & Educational. Context \\
\hline Évaluation par les usagers & Annotation. Description \\
\hline
\end{tabular}




\section{Taxonomy}

Unlike a number of recent learning object repository projects, FLORE is not seeking in any way to fully support the use of all 76 data elements in the LOM. The support of all 76 LOM elements and the complex data structures through which they are interrelated has proven to be very difficult using conventional database technologies (Friesen, 2005). The developers of the FLORE repository have deliberately chosen to steer clear of this costly technical challenge. But at the same time, these developers have elected to leverage a number of LOM elements in a special manner by developing a subject taxonomy relevant specifically to the teaching of French in Canada and other countries in the commonwealth of French countries, or the Francophonie. This taxonomy will be used under the category "domaines" (referred as "General.Keyword" in LOM/CanCore), and is shown in Table 2 .

Table 2: Sample of New Taxonomy

\begin{tabular}{|l|l|}
\hline FLORE DOMAINES/ FIELDS & FLORE SOUS-DOMAINES/ SUB-FIELDS \\
\hline Littérature & Française \\
& Canadienne \\
& Africaine \\
& Caraïbes \\
& Autres [Francophone (Suisse, Belge, etc)] \\
\hline Grammaire & Adjectif \\
& Adverbe \\
& Conjonction \\
& Déterminant \\
& Interrogation \\
& Nom \\
& Préposition \\
& Pronoms \\
& Verbes et conjugaisons \\
& Autres \\
\hline
\end{tabular}

Furthermore, the "Classification" data element category in the LOM was adapted in a number of ways in order to ensure a closer relationship between FLORE's learning objects and the potential contexts in which they are put to use. The first and most important of these was the introduction of a small but significant element vocabulary, referring to the level of communicative competence that corresponds to the target audience of a learning object. Unlike many other areas of intellectual skill and ability (e.g. writing or reading in one's native language), competence level in a second language is generally quite independent of other audience attributes such as age range or context. Clearly registering this competence is fundamental for language learning because users need to be able to access resources that are specific to their level of comprehension. A second adaptation of the classification element category was made in order to clearly indicate the type of language learning environment for which the LO may be most suitable. For instance, it is often the case that learners studying in an immersion setting have different needs from those studying French as a foreign language. 


\section{FLORE's Contents}

The selection of learning objects to be included in FLORE is based on a series of explicit criteria. Despite the significant number of resources that have been selected for the repository, these criteria follow the general principle of placing "quality before quantity." The current criteria for the selection of sites and learning objects in FLORE are as follows:

a. The resource is appropriate for post-secondary education and can be identified as appropriate for one of the following competency levels: beginner/ intermediate/ advanced/ expert;

b. The resource is regularly maintained by its author(s);

c. The quality of the linguistic content is high (i.e. there are no [or minimal] language or linguistic errors);

d. The resource is relevant to learning or teaching French and can be readily described according to the metadata used in this project;

e. The resource contains and serves clear objectives or outcomes;

f. The resource does not contain pop-ups and little or no advertising;

g. The resource was developed specifically to address a pedagogical need;

h. The resource's interface is easy to use/navigate;

i. The resource is platform independent;

j. The resource was developed by an educator (this is a preference not an obligation).

These criteria can be seen as presenting an implicit definition for the concept "learning object." Unlike many conventional definitions, a LO, according to these criteria, is not something that is defined by its qualities as a reusable software component. Instead, such a "Learning Object" is a resource that has a specifiable educational application, that is compatible with conventional Internet and computer technologies, and that provides content of high quality.

\section{FLORE's Interface and Functionalities}

\section{Interface}

The Web interface for FLORE, available in French and in English, has been developed in three steps. The original interface was text-based and included many options and functions. Experiments with students showed that they actually preferred fewer interface elements (Caws, 2005). A simplified and more graphically-oriented interface was therefore subsequently implemented. This resulted in increased user satisfaction but also slowed site response-times. This prompted us to transform the site, simplifying the graphical interface further, and leading us to the present interface, based on open-source PHP technology. Figure 1 indicates the functionalities that are available, first for unregistered users, and second, for registered users. Registration is simple and free, and provides the user with the possibility of individualizing the site (Beaudoin, 2004), thus raising the level of interactivity (Chanier, 2000).

\section{Functions}

Unregistered users can access basic search, advanced searches, and a list ten most popular LOs in the repository. The basic search function is available from any screen. Searches can be performed based on the field of study, on the author, or on any other metadata element. The advanced search function offers the opportunity to search the field of study in the form of checkbox options, the title, the description, the author, the URL, and the level of competence in French as shown in Figure 2. 

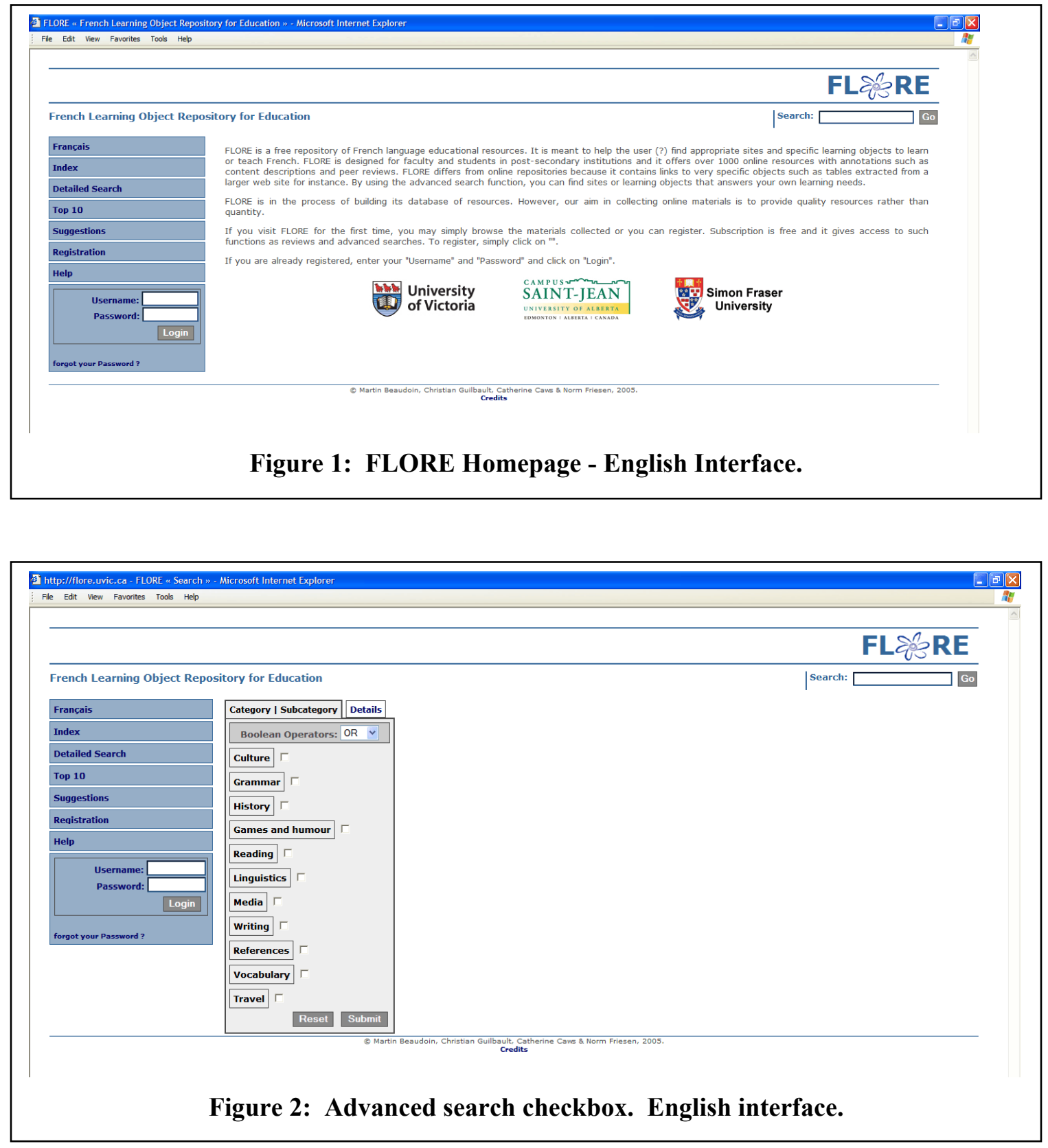

Boolean operators are available in the advanced search function, and registered users can suggest sites (See Figure 3). This is important since users are often aware of valuable resources. Authors may also submit their own objects for review.

Registered users have access to all functions described above, plus functions that provide individualization and a removal of the limit on the number of objects resulting from a search. The most popular of these functions is the bookmark feature (See Figure 4). It allows users to maintain links to their favorite resources and to organize their bookmarks by categories. Bookmarks can be shared with other users, and can be utilized as a way to promote exceptional resources. Registered users can also access a listing of objects they recently visited, along with the date and time of visit. Finally, registered users can evaluate a LO; an average of the scores given through such user evaluations is shown in the details of the LO. 


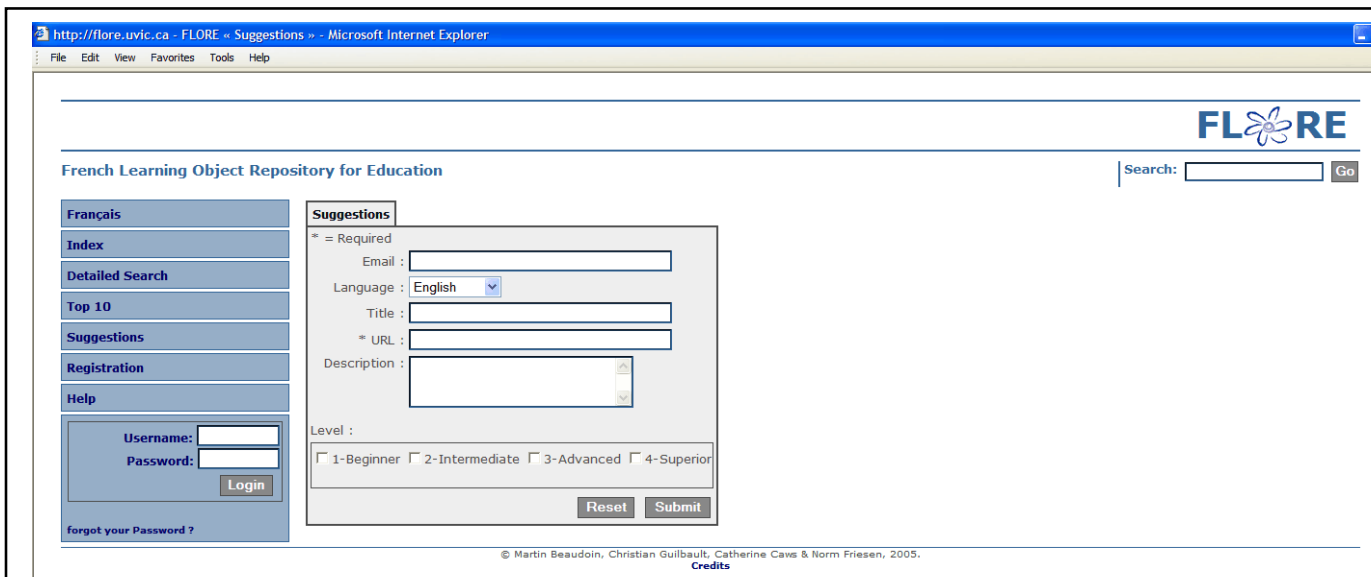

Figure 3: Site Suggestion Function. English Interface.

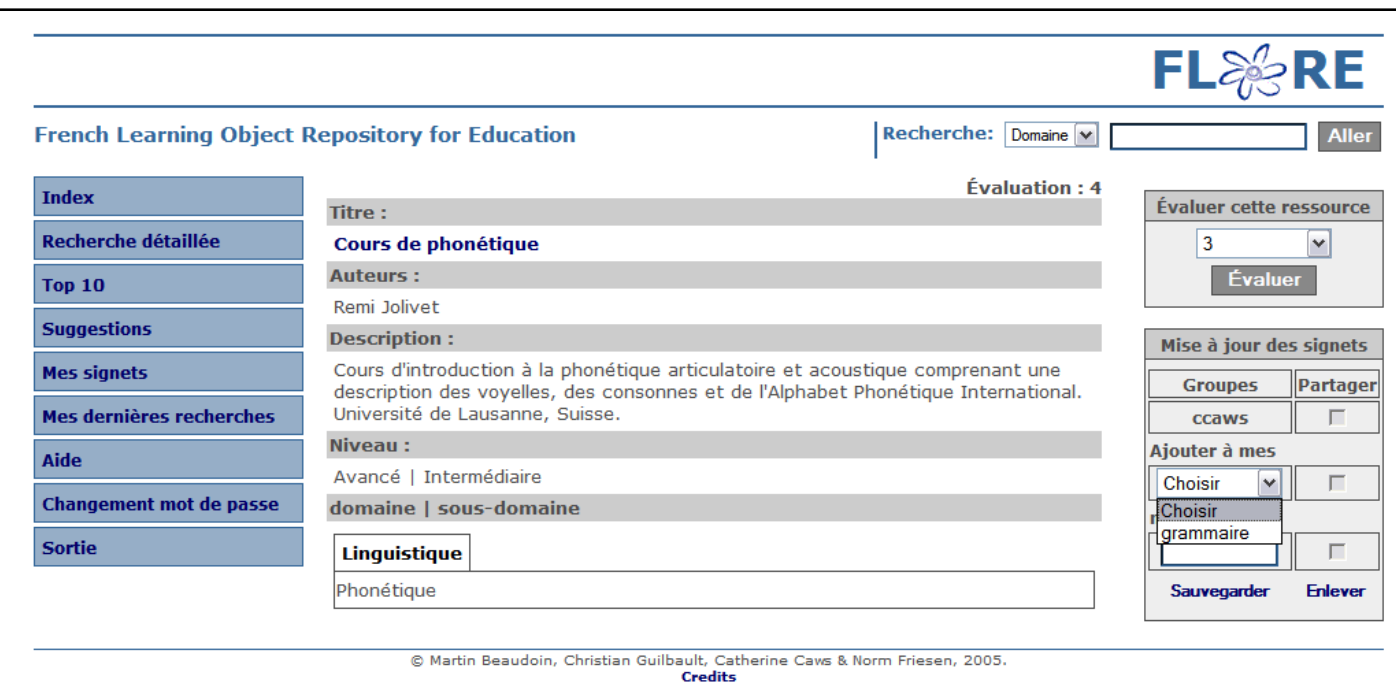

Figure 4: Book marking function. French interface.

One additional functional area is presented by Application Program Interfaces (APIs) that would connect the repository to other repositories, and that would make its search and other functions available to systems for Learning Management (LMSs) and other pedagogical functions. Of these, FLORE has so far only been explicitly concerned with addressing repository networking interfaces. The FLORE project plans to develop or modify an already developed tool that supports the Open Archive Initiative's Metadata Harvesting Protocol (the OAI-MHP). This lightweight protocol will allow FLORE to share metadata records with other repositories asynchronously, and would make it possible to link its metadata store with repository/library networks such as the Canadian Association of Research Libraries (CARL) Harvester network. This protocol also presents the possibility of being modifiable to accommodate other, even more simple protocols such as RSS. 


\section{FLORE's Research and Development Orientation}

\section{The Issue of Context}

As mentioned earlier, one of the original goals of the FLORE project was to address a common short-coming identified in repository and learning object projects and approaches: their removal from the context-laden realities and activities of learning and education. As was explained above, the idea of creating modular, reusable learning resources, and classifying and storing them in a central repository generally entails their removal and decontextualization from the contexts and practices that give them their educational value in the first place. Yet Wiley (2003), who was the first to clearly identify this "paradox," also notes that this challenge can be partially solved through an alternative approach: "rather than studying learning objects out of context, the research unit of analysis [can focus instead] on learners' actual uses of [existing] objects within a learning context" (p.3).

The research component of the FLORE project seeks to restore this context precisely as Wiley has recommended. One of the ways that repository and learning object designs have led to a decontextualization generally is by attempting to serve all educational subjects and sectors equally. Learning object repository and repository infrastructure projects such as CAREO have had as their ambitious goal in the creation of systems appropriate for any subject area and for multiple age-levels in education. However, in attempting to accommodate everyone, these projects have faced the challenge of also serving no one in particular. The question of creating one or more "communities of practice" --of subject specialists and teacher-practitioners-- who will actively use the repository, has become, in these contexts, a serious challenge. In the end, such projects may have become most closely associated with the post-secondary educational technology developer and research communities in which they have their origin, rather than in any communities of practice for which there were originally envisioned.

FLORE is quite different in this regard. Developed initially by French language instructors to meet the needs of other instructors in French, this project has a clearly defined audience or community ready-made for its purposes. There is therefore no great need to conceptualize or develop "communities of practice" around the repository. Given the obvious importance of Frenchlanguage education in Canada and in the Francophonie in general, this audience and its needs are stable and very clearly defined. Something similar can be said to apply in terms of the resources or learning objects collected and systematically described in FLORE. As indicated above, this project is able to safely side-step the lengthy debates regarding the precise definition of "learning objects" and their "reuse" that have plagued many in the educational technology community. There are many resources on the Web that have been created specifically for French language instruction, and that have been used successfully in these contexts. Such resources --whether a database of verb conjugations, or a simple list of words or idioms-- have in most cases clear educational contexts and applications. Although such resources cannot be as readily reused or repurposed for entirely unexpected or novel uses --or dynamically recombined as more modular or technically sophisticated "objects" might-- their educational purpose and utility is clear.

The focus of FLORE on French language instruction specifically in higher-education settings provides this repository with the "context" that Wiley (2003) identifies as being absent in some conceptions of learning objects and repositories. This context of instructional use has already been the focus of research activities in FLORE, and will remain so in the future. This is reflected in the preliminary research that has already been undertaken. For example, a detailed evaluation (Caws, 2005) was used to target as precisely as possible the needs and perceptions of current and potential users of FLORE. In addition, it is to be noted that by creating a system based on a predetermined context (e.g. French), its development can have a direct impact on other disciplines 
and in particular any second languages. Indeed the repository's functions and the system's architecture could be replicated to describe and organize other discipline based content.

\section{Research Methodology}

The research methodology used to test the efficacy of the technology is based on the design experiment model initially developed by Brown (1992). Because design experiments are based on revision and continuous cycles of refinement and further development of the object of study, they present many advantages over experimental designs using pre- and post-tests where the treatment cannot be changed to maximize the intervention's effectiveness. Cobb, Confrey, DiSessa, Lehrer, and Schauble (2003) explain that "Design experiments ideally result in greater understanding of a learning ecology- a complex iterating system involving multiple elements of different types and levels- by designing its elements and by anticipating how these elements function together to support learning" (p. 9). Figure 5 illustrates the research design and its application to the development and expansion of FLORE:

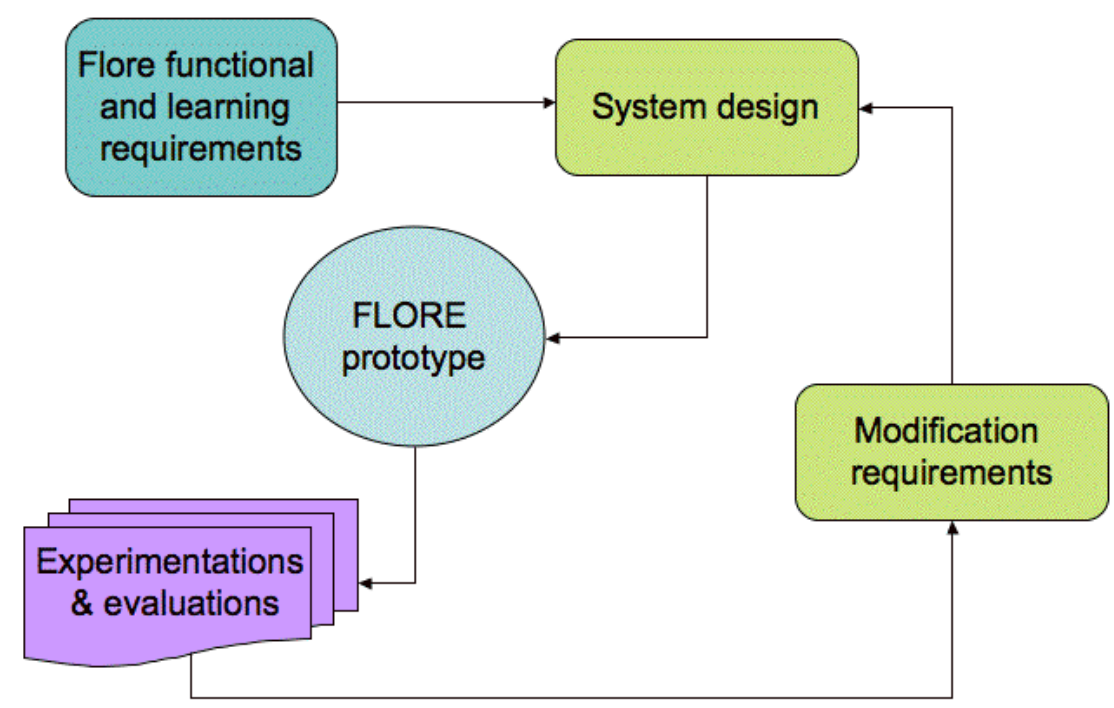

Figure 5: Integration of the research into the LOR development

The value of evaluating educational environment has been recognized by several studies and, as explained by Nesbit, Berfert, and Vargo (2002), in the case of LORs, it can become a challenging process when the evaluation seeks to address the high number of resources available.

\section{Pilot studies}

Two pilot studies were initiated to test the original FLORE infrastructure and our application of this methodology: one in the spring of 2004 and one in the fall of 2004 involving a total of 18 subjects (11 teachers, 7 students). Participants were selected at random following a call for participation to teachers of French at the University of Victoria and Simon Fraser University (spring 2004) and to students of French in first year at the University of Victoria (fall 2004). Throughout these pilot assessments, data were gathered from student and/or teacher participants through questionnaires containing questions on a 5 point Likert scale, as well as multiple choice questions and open-ended questions -all designed to stimulate a process of reflective practice (see Appendix). 
The Likert scale technique is commonly used in questionnaires to collect data about attitudes towards learning within a specific setting or, in the case of technology, learning using a specific system. Favorable attitudes towards the system or learning environment are reflected in higher scores. Student participants also had the opportunity to reflect on their experience through journaling or by way of focus group interviews. These two pilot studies helped us determine what users like and did not like in the LOR, how they viewed its benefits or whether they could perceive major drawbacks in the system.

\section{Results}

When analyzing both quantitative and qualitative data, we looked for trends in the perceived benefits and disadvantages of using the LOR for teaching and/or learning. For the purpose of this article, we report on items where the qualitative comments supported the results of the questionnaire (See Table 3).

Table 3: Participants Ratings on Selected Items

\begin{tabular}{|l|c|c|}
\hline \multicolumn{1}{|c|}{ Item } & $\begin{array}{c}\text { Teacher's rating } \\
\mathbf{N = 1 1}\end{array}$ & $\begin{array}{c}\text { Students ratings } \\
\mathbf{N = 7}\end{array}$ \\
\hline Quality of the sites or learning objects in FLORE & 3.5 & 4 \\
\hline Evaluation of resources in FLORE & 4.13 & 3.86 \\
\hline Description of resources in FLORE & 4.36 & 4.29 \\
\hline Level of resources & 4 & 4 \\
\hline
\end{tabular}

In the survey, students reported general satisfaction regarding both the content and interface of FLORE. The quality and diversity of items found in the repository was considered satisfactory for both teachers and students --in the context of both specific courses and more general programs of study. Teachers were particularly keen on having the option to evaluate learning objects found in the repository and to be able to suggest possible resources. These results transpired both in the participants' own reflections as well as in the numerical scoring as shown in Table 3.

These preliminary results are congruent with Nesbit et al.'s study (2002) in which the authors emphasize the value of learning objects evaluation by third parties. These same authors further argue that only an elaborate system of evaluation can produce quality resources. In our current system, the evaluation process is fairly simple, that is, based on a numerical rating. However to better address issues of qualitative evaluation, we are looking at implementing a new feature for the evaluation process based on qualitative assessment produced by three independent reviewers. Following the example of MERLOT, this will likely be a type of "peer review," similar to those routinely undertaken for academic publications and grant applications.

Users also indicated that the metadata used to describe the resources were effective. These results are of critical importance for the further development of the metadata and the associated search capabilities of the system in keeping with its situated use. Both teachers and students made specific comments regarding the organization of the information, and the design of the pages. In general, users wanted to have more flexibility in their search, and more individualization features, allowing them to adapt the system to their learning or teaching preferences. These and other observations have been addressed and are currently being tested and implemented. A further series of evaluations by users will help us determine the appropriateness of the modifications to the system. 


\section{Conclusion}

The collection of such feedback --and its use in iterative design processes-- is indispensable for relocating learning objects back into their context. Only by exploring how practices adapt to this new learning technology --and technologies can be adapted to these practices-- is it possible to develop a more complete understanding of the relationship between the user and the learning tools. This includes the design and use of interfaces, practices of interaction, and the efficacy of associated activities and designs. Speaking specifically of digital educational technologies, Bates (2000) states: "Research that focuses on the requirements for the effective use of a particular technology will be helpful. Such research might focus on forms and levels of student-machine interaction, interface design, and designs that support learners working in isolation" (p. 200). This view is shared by Nash (2005) who reiterates the need to create an alignment between the development of LOs and their application to teaching and learning. Such a process would ensure that a LO could be paired with specific learning outcomes within a specific learning theory. Following these premises, we have implemented a research methodology within which users' feedback is invaluable to the proper development of both the technical functionality of the system and its pedagogical application(s).

Both scholars and practitioners in educational technologies are increasingly recognizing the importance of empirically evaluating technology. Warschauer (2003) stated that "technology does not exist as an external variable to be injected from the outside to bring about certain results" (p. 47). Instead, technologies --the Internet, learning objects, or other innovations-- realize their educational potential through a process of mutual suffusion and infusion. These processes imply that the technology is adapted as a part of the learning or educational process, affecting both the actual use and the original conception of the technology. Consequently, it is important to follow Bates' (2000) advice that "new technologies for teaching do need to be researched and evaluated, but the evaluation should not be restricted merely to replicating classroom learning outcomes" (p.201). Research, as Bates' statement implies, needs to be attuned to the way that the integration of technologies in teaching practice will change educational settings, and will also change the outcomes and even the technologies themselves. Only in this sense can these technologies be said to reciprocally infuse and inform teaching and learning practices. It is the ultimate intention of the FLORE project to both realize and direct investigative attention to these intricate processes.

Future research is needed to properly direct the development of FLORE as a LOR, and to address new challenges that arise. To further address the aspects of contextualization and LOR efficacy in language teaching, we must also investigate the role that FLORE can play in specific relation to learners' language learning. Only by embedding a LOR into a proper learning theory and teaching practice can we truly address all challenges that are surfacing as both repositories and objects continue to be developed and deployed.

\section{References}

Bates, A.W. (2000). Managing technological change: Strategies for college and university leaders. San Francisco: Jossey-Bass.

Beaudoin, M. (2004). A principle-based approach to teaching grammar on the web. ReCALL, 16(2), 462474.

Blandin, B. (2004). Are e-learning standards neutral? International Conference on Computer Aided Learning in Engineering Education. Retrieved March 22, 2005 from http://wwwclips.imag.fr/calie04/actes/Blandin_final.pdf

Brown, A. L. (1992). Design experiments: Theoretical and methodological challenges in creating complex interventions in classroom settings. Journal of the Learning Sciences, 2(2), 141-178. 
Caws, C. (2005). Evaluating a learning objects repository: A pilot study. The IALLT Journal of Language Learning Technologies, 37(1), 51-62.

Chanier, T. (2000). Hypermedia, interaction et apprentissage dans des systèmes d'information et de communication: résultats et agenda de recherche. In L. Duquette \& M. Laurier (Eds.), Apprendre une langue dans un environnement multimédia. Outremont, Québec: Les éditions logiques.

Cobb, P., Confrey, J., DiSessa, A., Lehrer, R., \& Schauble, L. (2003). Design experiments in educational research. In A. Kelly (Ed.), Educational Researcher, 32(1), 9-13.

de Salas, K. \& Ellis, L. (2006) The development and implementation of learning objects in a higher education setting. Interdisciplinary Journal of Knowledge and Learning Objects, 2, 1-22. Retrieved August 20, 2006 from http://www.ijklo.org/Volume2/v2p001-022deSalas.pdf

Friesen, N. (2004). Three objections to learning objects. In R. McGreal (Ed.), Online education using learning objects (pp. 59-70). London: Routledge Falmer.

Friesen, N. (2005). Interoperability and learning objects: An overview of e-learning standardization. Interdisciplinary Journal of Knowledge and Learning Objects, 1, 23-31. Retrieved from http://ijklo.org/Volume1/v1p023-031Friesen.pdf

Harman, K., \& Koohang, A. (2005). Discussion board: A learning object. Interdisciplinary Journal of Knowledge and Learning Objects, 1, 67-77. Retrieved August 19, 2006 from http://www.ijklo.org/Volume1/v1p067-077Harman.pdf

McGreal, R., \& Roberts, T. (2001). A primer on metadata for learning objects: Fostering an interoperable environment. E-learning, 2(10), 26-29. Retrieved July 14, 2002 from http://elearningmag.com/elearning/article/articleDetail.jsp?id=2031

Mortimer, L. (2002). (Learning) objects of desire: Promise and practicality. Learning Circuits. Retrieved April 1, 2005, from http://www.learningcircuits.org/2002/apr2002/mortimer.html

Namuth, D., Fritz, S., King, J., \& Boren, A. (2005). Principles of sustainable learning object libraries. Interdisciplinary Journal of Knowledge and Learning Objects, 1, 181-196. Retrieved August 20, 2006, from http://www.ijklo.org/Volume1/v1p181-196Namuth.pdf

Nash, S. S. (2005). Learning objects, learning object repositories, and learning theory: Preliminary best practices for online courses. Interdisciplinary Journal of Knowledge and Learning Objects, 1, 217-228. Retrieved from http://ijklo.org/Volume1/v1p217-228Nash.pdf

Nesbit, J. C., Belfer K. \& Vargo, J. (2002). A convergent participation model for evaluation of LOs. Canadian Journal of Learning and Technology, 28(3), 105-120.

Rehak, D. \& Mason, R. (2003). Keeping the learning in learning objects. In A. Littlejohn (Ed.), Reusing online resources: A sustainable approach to e-learning. London: Kogan Page.

Richards, G., McGreal, R., Hatala, M., \& Friesen, N. (2002). Learning object repository technologies: Portals for on-line objects for learning. Journal of Distance Education, 17(3), 67-79.

Warschauer, M. (2003, August). Demystifying the digital divide. Scientific American, 42-47.

Wiley, D. (2003). Learning objects: Difficulties and opportunities. Retrieved March 15, 2005 from http://wiley.ed.usu.edu/docs/lo do.pdf

Wiley, D. (2005). Pedagogy-agnostic standards and a much needed rant. Retrieved June 15, 2005 from http://wiley.ed.usu.edu/archies/145

Wiley, D., Gibbons, A., \& Recker, M. (2000) . A reformulation of the issue of learning object granularity and its implications for the design of learning objects. In D. A. Wiley (Ed.), The instructional use of learning objects. Bloomington, Indiana: Agency for Instructional Technology and Association for Educational Communications of Technology. 


\section{Appendix \\ FLORE Survey- Questions Sample}

$1=$ Completely disagree $\quad 5=$ Completely agree

1. FLORE interface made my search easy.

2. FLORE interface has all the functions I need.

3. I find it motivating to work in FLORE.

4. I believe that other students would like to use FLORE.

5. I believe FLORE can help me with my study of the French language.

6. I like the fact that I can evaluate sites or learning objects in FLORE.

7. The organisation of the content in FLORE is efficient

8. The content of the learning objects in FLORE were useful.

9. The quality of the sites or learning objects in FLORE were high.

10. There was a good selection/variety of sites or learning objects in FLORE.

11. I found exactly the learning objects that I was looking for in FLORE.

12. The evaluation on a scale of 1 to 5 for each site in FLORE is appropriate.

13. The description of the site or learning objects in FLORE is fair.

14. The description of the site or learning objects in FLORE is useful.

15. The level associated to each site or learning objects in FLORE is appropriate.

$\begin{array}{lllll}1 & 2 & 3 & 4 & 5 \\ 1 & 2 & 3 & 4 & 5 \\ 1 & 2 & 3 & 4 & 5 \\ 1 & 2 & 3 & 4 & 5 \\ 1 & 2 & 3 & 4 & 5 \\ 1 & 2 & 3 & 4 & 5 \\ 1 & 2 & 3 & 4 & 5 \\ 1 & 2 & 3 & 4 & 5 \\ 1 & 2 & 3 & 4 & 5 \\ 1 & 2 & 3 & 4 & 5 \\ 1 & 2 & 3 & 4 & 5 \\ 1 & 2 & 3 & 4 & 5 \\ 1 & 2 & 3 & 4 & 5 \\ 1 & 2 & 3 & 4 & 5 \\ 1 & 2 & 3 & 4 & 5\end{array}$

\section{Biographies}

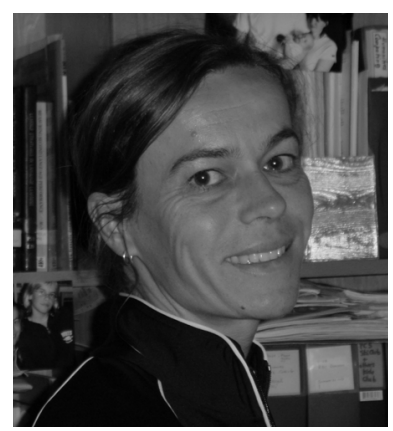

Dr. Catherine Caws is an assistant professor in the Department of French at the University of Victoria. Dr. Caws conducts research in second language teaching at the post-secondary level, computerassisted language learning, and computer networking. She is currently involved as principal investigator in a collaborative project, funded by the Research and Development Initiative program of the Canadian Social Science and Humanities Research Council, which seeks to study the Learning and Teaching Impact of a French Learning Object Repository. 


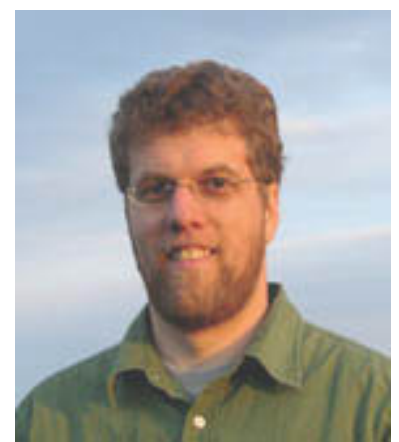

Dr. Norm Friesen has been involved with Web technologies in education since 1995. Norm is currently a SSHRC Postdoctoral Fellow at the School of Communication at Simon Fraser University, and the principal investigator in the "learningspaces.org" project sponsored by SSHRC (the Social Sciences and Humanities Research Council of Canada). Norm is also an Adjunct Faculty member at Athabasca University, Canada's Open University, and has recently been a visiting scholar at the Faculty of Information Studies at the University of Toronto, and at the Leopold Franzens University, Innsbruck, Austria. In addition to authoring dozens of articles and reports, Norm has produced several editions of books on the instructional use of WebCT and on the implementation of the IEEE Learning Object Metadata standard.

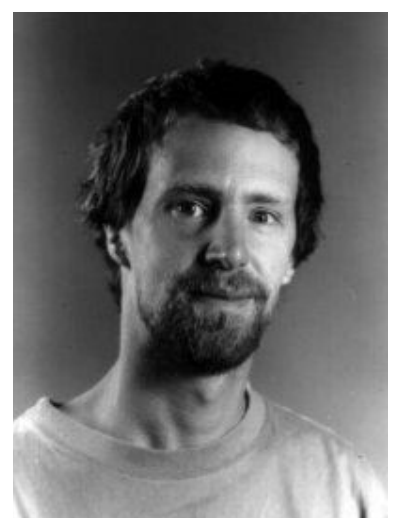

Dr. Martin Beaudoin holds a Ph.D. in Romance Linguistics from the University of Alberta. He has specialized in Second Language Learning with a keen interest in Computer Assisted Language Learning. He currently leads a number of multimedia projects, including Pomme (www.pomme.ualberta.ca) and Le Devoir conjugal (www.pomme.ualberta.ca/devoir). He teaches French and Linguistics at Faculté Saint-Jean, University of Alberta. 